\title{
Reagent Generation Assisted by Ultrasonic Irradiation
}

\author{
Mauro Korn ${ }^{*, a}$, Marta V. A. S. Andrade ${ }^{a}$, Sivanildo S. Borges ${ }^{b}$, Clarivaldo S. Sousa ${ }^{b}$ and \\ Fábio S. Oliveira ${ }^{b}$ \\ ${ }^{a}$ Departamento de Ciências Exatas e da Terra, Universidade do Estado da Bahia, Estrada das Barreiras s/n, \\ 41195-001 Salvador - BA, Brazil \\ ${ }^{b}$ Instituto de Química, Universidade Federal da Bahia, Campus Universitário de Ondina, \\ 40.170-290 Salvador - BA, Brazil
}

\begin{abstract}
Neste trabalho a capacidade de geração de reagentes em sistemas assistidos por ultra-som é apresentada e avaliada para a oxidação de cromo e a formação de arsina. Os processos envolvidos na formação de radicais livres produzidos em soluções aquosas pela ação sonoquímica foram avaliados. A sonicação de solução aquosa de $\mathrm{CCl}_{4}$ leva à formação de radicais cloro, enquanto que a irradiação da água na presença de zinco metálico leva à produção de hidrogênio. O baixo desvio padrão relativo dos procedimentos propostos indica que o método pode ser aplicado para propósitos analíticos.

In this work, the potential of reagent generation assisted by ultrasonic irradiation was evaluated for $\mathrm{Cr}$ (III) oxidation and arsine formation. Free radical formation by sonolysis of aqueous solutions was evaluated. The sonication of an aqueous solution saturated with $\mathrm{CCl}_{4}$ leads to chlorine radical formation while the irradiation of water in the presence of metallic zinc leads to hydrogen production. The low relative standard deviations of the proposed procedures indicate that the method can be applied for analytical purposes.
\end{abstract}

Keywords: reagent generation, ultrasonic irradiation, free radicals, hydride, chromium oxidation

\section{Introduction}

The generation of reagents in situ can not be considered an usual procedure for chemical analysis, since only a few techniques, such as gravimetric methods based on precipitation from homogeneous solution, apply this perspective. However, the application of a system in situ generation is important when the reagent produced is either unstable or when its use can affect the environment or the operator's health.

Free radicals can be generated as a consequence of the cavitation induced by ultrasonic waves. In this way, radicals can be considered as the primary reagents produced by ultrasound. Several studies have demonstrated that $\mathrm{H}_{2} \mathrm{O}_{2}$, $\mathrm{HNO}_{2}$ and $\mathrm{HNO}_{3}$ are produced by the association and rearrangement of hydroxyl radicals reacting with dissolved $\mathrm{N}_{2}$ and $\mathrm{O}_{2}$ when water saturated with air is sonicated. ${ }^{1-3}$ The hydroxyl radicals are formed by water sonolysis, and the generation rate of the products depends on the nature and concentration of the gases dissolved in the solution,

* e-mail: mkorn@campus1.uneb.br on the ultrasonic wave frequency and power, and on the pressure and temperature of the medium. ${ }^{4}$ Ultrasonic radiation can induce production of oxidizing species in order to improve some analytical procedures. ${ }^{5}$ This is worthwhile in procedures based on oxidation reactions, as some electron acceptor species - e.g. the hydroxyl radical - are generated in the sonicated solution.

In this work analytical procedures improved by ultrasonic irradiation are presented for $\mathrm{Cr}$ and $\mathrm{As}$ determinations in waste water and biological samples, respectively. For these procedures, ultrasonic irradiation processes were conducted in an aqueous media, and the effect of the free radicals produced, $\mathrm{Cl} \bullet$ and $\mathrm{H} \bullet$, was evaluated by comparison with the conventional methods for $\mathrm{Cr}$ (III) and As (III) determination.

Theory

Ultrasound in analytical processes has usually been employed using an ultrasonic cleaner bath, in the preanalytical steps (e.g., bottle cleaning, slurry and emulsion production) and the sample preparation steps (extraction, 
leaching and dissolution of solids), ${ }^{6-8}$ since the acoustic waves increase the interaction of solvent with the solid surfaces by mechanical phenomena. However, the chemical effects promoted by ultrasonic irradiation in aqueous media, under the proper conditions, have not yet been employed in the decisive determination step of an analytical procedure. As described elsewhere, ultrasonic irradiation leads to the formation and collapse of gas or vapor filled bubbles in the medium. ${ }^{1,2}$ The collapse of the bubbles can be considered as extremely powerful, allowing an increase of the local temperature and pressure to 5200 $\mathrm{K}$ and $80 \mathrm{MPa}$, respectively. ${ }^{9}$ Several chemical phenomena related to the effects of ultrasonic irradiation on solutions have been observed. These effects include electron transfer processes, molecular degradation and free radical generation. ${ }^{1}$ Free radical generation is shown by the production of $\mathrm{Fe}(\mathrm{III})$ from $\mathrm{Fe}$ (II) ions and by the formation of $\mathrm{I}_{3}^{-}$from a KI solution, both of which occur as a consequence of the formation of oxidizing species in aqueous solutions irradiated with ultrasound. ${ }^{10,11}$ Furthermore, ultrasound was applied for the degradation of several inorganic polymers, such as molybdate, in an acidic medium. ${ }^{12}$

\section{Experimental}

\section{Equipment}

Two commercial ultrasonic cleaner baths, Aquasonic 75D (VWR) and Bransonic 1510 (Cole Parmer), were employed to irradiate the solutions at $40 \mathrm{kHz}$. A 432 Femto spectrophotometer equipped with glass cuvettes $(10 \mathrm{~mm}$ optical path) was employed for absorbance measurements. A Minipuls 3 (Gilson) peristaltic pump was employed for solution propulsion in the flow systems. Temperature control was carried out by a thermostatic bath model TE184 (Tecnal). pH measurements were performed using a Checker 1 Hanna pHmeter equipped with a glass electrode.

Reactor vessels made of borosilicate were employed for the studies involving solvent sonolysis for hydride and chlorine generation.

\section{Reagents and solutions}

All chemicals used were of analytical grade and the solutions were prepared using deionized water. For the evaluation of chlorine radicals generated by the sonication of water saturated with $\mathrm{CCl}_{4}$ several solutions were prepared.

Stock solutions containing $1000 \mathrm{mg} \mathrm{L}^{-1}$ of $\mathrm{Cr}(\mathrm{VI})$ and $\mathrm{Cr}$ (III) were prepared using $\mathrm{K}_{2} \mathrm{Cr}_{2} \mathrm{O}_{7}$ and $\mathrm{CrCl}_{3}$, respectively.
Standard solutions from 0.1 to $6.0 \mathrm{mg} \mathrm{L}^{-1} \mathrm{Cr}$ (III) were prepared by the proper dilution of the stock solution. The chromate complexing reagent solution was prepared by dissolving $0.05 \mathrm{~g}$ of 1,5-diphenylcarbazide in $2 \mathrm{~mL}$ of acetic acid and diluting to $25 \mathrm{~mL}$ with water. $\mathrm{NaHCO}_{3}$ was used to prepare a $0.01 \mathrm{~mol} \mathrm{~L}^{-1}$ solution.

For the evaluation of arsine generation by the sonication of water, other solutions were prepared. An As(III) stock solution, $1000 \mathrm{mg} \mathrm{L}^{-1}$, was obtained as Titrisol standard solution (Merck). Standard solutions from 0.1 to $1.5 \mu \mathrm{g} \mathrm{mL}^{-1} \mathrm{As}$ (III) were prepared by proper dilution of the stock solution. Silver diethyldithiocarbamate (Ag-DDTC) solution was prepared by dissolving $0.5 \mathrm{~g} \mathrm{Ag}$-DDTC (Merck) in $100 \mathrm{~mL}$ of pyridine (Reagen) at $60{ }^{\circ} \mathrm{C}$. A $4 \mathrm{~mol} \mathrm{~L}^{-1} \mathrm{HCl}$ solution was prepared by the proper dilution of concentrated analytical grade acid. Powdered zinc (Merck) was used for hydride generation.

\section{Experimental procedures}

All glassware and bottles used were cleaned in a $1.8 \mathrm{~mol} \mathrm{~L}^{-1} \mathrm{HNO}_{3}$ solution for 12 hours and rinsed with deionized water before use.

Ultrasonic irradiations were conducted in the central zone of the ultrasonic bath, as discussed elsewhere..$^{13}$

In order to evaluate the effect of chlorine radicals on chromium oxidation, deionized water saturated with $\mathrm{CCl}_{4}$ was obtained by adding 2 drops of this reagent to $400 \mathrm{~mL}$ of water and stirring the mixture for 2 hours at $25^{\circ} \mathrm{C}$. This aqueous solution, satured with $\mathrm{CCl}_{4}$, was used throughout. $1 \mathrm{~mL}$ of $\mathrm{Cr}^{3+}$ solution and $500 \mu \mathrm{L}$ of $0.01 \mathrm{~mol} \mathrm{~L}^{-1} \mathrm{NaHCO}_{3}$ were placed in a $5 \mathrm{~mL}$ volumetric flask and the volume was taken to the mark with the $\mathrm{CCl}_{4}$-saturated aqueous solution. This solution was transferred to a $10 \mathrm{~mL}$ borosilicate beaker (i.d. $=22 \mathrm{~mm}$, o.d. $=24.5 \mathrm{~mm}, \mathrm{~h}=36$ $\mathrm{mm}$ ) for irradiation. Sonication periods up to $10 \mathrm{~min}$ were evaluated and the temperature was maintained at $25^{\circ} \mathrm{C}$, during sonication, by constant circulation of the water using the pump of thermostatic bath to propel and the ultrasonic bath drain to maintain the same level of water. After irradiation, $200 \mu \mathrm{L}$ of $1 \mathrm{~mol} \mathrm{~L}^{-1} \mathrm{H}_{2} \mathrm{SO}_{4}$ and $500 \mu \mathrm{L}$ of 1,5-diphenylcarbazide solution were added to the beaker to complex any $\mathrm{Cr}(\mathrm{VI})$ formed. Analytical signals were measured at $540 \mathrm{~nm}$.

The evaluation of arsine formation assisted by ultrasonic irradiation from an aqueous As(III) solution was performed in an acidic medium in the presence and absence of metallic $\mathrm{Zn}$. The optimization was performed by a $2^{3}$ factorial design. In order to characterize the formation of Ag-DDTC-As by the reaction of Ag-DDTC with the $\mathrm{AsH}_{3}$ produced during the sonication, $500 \mu \mathrm{L}$ of a 
$100 \mu \mathrm{g} \mathrm{mL}^{-1} \mathrm{As}(\mathrm{III})$ solution were diluted to $100 \mathrm{~mL}$ with dilute $\mathrm{HCl}$ solution $\left(1 \times 10^{-4}\right.$ to $\left.1 \times 10^{-1} \mathrm{~mol} \mathrm{~L}^{-1}\right)$. The final solution, also containing metallic zinc $(0.1$ to $1 \mathrm{~g})$, was placed in the reactor vessel (Figure 1) at $25^{\circ} \mathrm{C}$. The reactor was closed and irradiated with $40 \mathrm{kHz}$ ultrasound (1 to 10 min). The $\mathrm{AsH}_{3}$ produced was pumped at $250 \mathrm{~mL} \mathrm{~min}^{-1}$ into a $10 \mathrm{~mL}$ volumetric flask containing Ag-DDTC solution, making use of an air compressor. The absorbance was measured at $535 \mathrm{~nm}$.

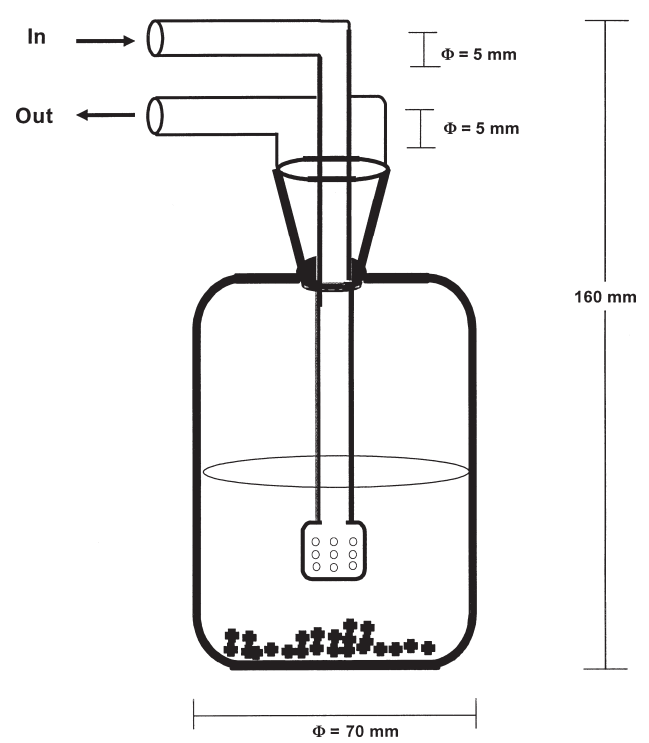

Figure 1. Reactor vessel for arsine generation. In - air pumped from diaphragm pump at $250 \mathrm{~mL} \mathrm{~min}{ }^{-1}$. Out - gas phase arsine to be captured in Ag-DDTC. \ represents powdered zinc.

The procedure was evaluated for determination of As in urine samples after pretreatment. $20 \mathrm{~mL}$ of urine sample were mixed with $1 \mathrm{~mL}$ of $5 \mathrm{~mol} \mathrm{~L}^{-1} \mathrm{H}_{2} \mathrm{SO}_{4}$ solution and $5 \mathrm{~mL}$ of $\mathrm{K}_{2} \mathrm{~S}_{2} \mathrm{O}_{8}$ solution $(5 \% \mathrm{w} / \mathrm{v})$ and heated. After cooling, the sample was transferred to a $10 \mathrm{~mL}$ volumetric flask and the volume was completed with water. After sample preparation, the resulting solutions were submitted to the same procedure as described above.

\section{Results and Discussion}

\section{Cr(III) oxidation by chlorine}

$\mathrm{Cr}$ (III) is easily oxidized to chromate in an alkaline medium, but implementing this procedure is not quantitative, due the formation of the hydroxides of $\mathrm{Cr}$ (III) and other metals that are precipitated in the basic solution. Therefore, oxidation of $\mathrm{Cr}$ (III) must be carried out in an acid media. $\mathrm{Cr}$ (III) is usually determined by reaction with 1,5-diphenylcarbazide, after oxidation to $\mathrm{Cr}$ (VI). The usual methods employ severe conditions to oxidize $\mathrm{Cr}$ (III), such as peroxydisulphate with $\mathrm{Ag}$ or permanganate, as $\mathrm{Cr}(\mathrm{III})$ is frequently stabilized by aqueous complex formation. Thus, an alternative oxidation procedure is needed.

The reactions involved in $\mathrm{CCl}_{4}$ sonolysis for $\mathrm{Cr}(\mathrm{III})$ oxidation include rupture of the $\mathrm{C}-\mathrm{Cl}$ bond (equation 1), followed the interaction between $\mathrm{Cl}$ radicals generated in the bubble and $\mathrm{Cr}$ (III) present in the bulk solution. Ultrasonic irradiation of aqueous $\mathrm{Cr}$ (III) solutions saturated with $\mathrm{CCl}_{4}$ leads to a pH decrease (equations 2 and 3 ) and to an increase in the concentration of $\mathrm{Cr}(\mathrm{VI})$ present (equation 4).

$$
\begin{aligned}
& \mathrm{CCl}_{4} \stackrel{)}{\rightarrow} \cdot \mathrm{CCl}_{3}+\cdot \mathrm{Cl} \\
& \cdot \mathrm{Cl}+\mathrm{H}_{2} \mathrm{O} \rightarrow \mathrm{HCl}+\cdot \cdot \mathrm{OH} \\
& \cdot \mathrm{Cl}+\cdot \mathrm{OH} \rightarrow \mathrm{HClO} \\
& \mathrm{Cr}^{3+}+3 \cdot \mathrm{Cl} \rightarrow \mathrm{CrO}_{4}^{2-}+3 \mathrm{Cl}^{-}
\end{aligned}
$$

The reaction expressed in equation 4 is a hypothetical route for $\mathrm{Cr}(\mathrm{VI})$ formation. Other mechanisms should be considered related to the interaction of aqueous or hydroxide containing $\mathrm{Cr}$ (III) complexes with chlorine radicals in the absence or presence of a powerful oxidizing species, such as Co(III).

The chlorine radicals produced during sonication of an aqueous solution of $\mathrm{Cr}(\mathrm{III})$ saturated with $\mathrm{CCl}_{4}$ at $\mathrm{pH}$ from 6.5 to 7.5 were capable of oxidizing $\mathrm{Cr}$ (III) after one min of ultrasonic irradiation. A $1 \times 10^{-2} \mathrm{~mol} \mathrm{~L}^{-1}$ carbonate buffer solution was used due to its inertia to $\mathrm{Cl}$ radicals. A mediator may be used to reach $100 \%$ of conversion of $\mathrm{Cr}(\mathrm{III})$ to $\mathrm{Cr}(\mathrm{VI})$. $\mathrm{Co}$ (II) played this role, having been first oxidized to $\mathrm{Co}(\mathrm{III})$ by chlorine radicals during sonication and then catalyzing the $\mathrm{Cr}$ (III) oxidation (Figure 2) .

Chromium oxidation was possible in the presence of several different sources of $\mathrm{Cl}$ radicals $\left(\mathrm{CCl}_{4}, \mathrm{CHCl}_{3}\right.$, and

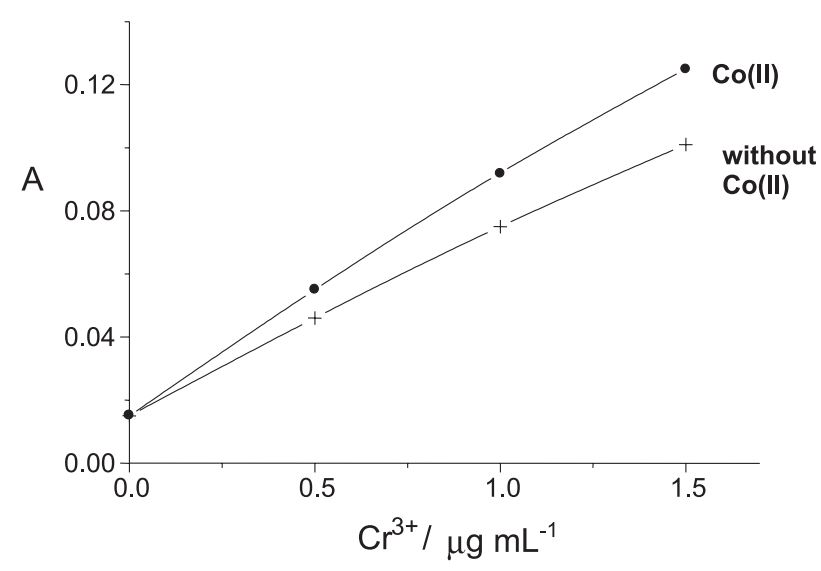

Figure 2. Effect of $\mathrm{Co}(\mathrm{II})$ on $\mathrm{Cr}(\mathrm{III})$ oxidation in $\mathrm{CCl}_{4}$ saturated aqueous solution for different $\mathrm{Cr}(\mathrm{III})$ concentrations, determined by the $\mathrm{Cr}(\mathrm{VI})$-DPC spectrophotometric method. $[\mathrm{Co}(\mathrm{II})]=10 \mu \mathrm{g} \mathrm{mL}^{-1}$. Irradiation time $=60 \mathrm{~s}$. 
$\mathrm{CH}_{2} \mathrm{Cl}_{2}$ ) and occurs quantitatively within one minute. However, without a chlorine radical producing reagent, although increasing the sonication time to $5 \mathrm{~min}$, chromium oxidation is not enough for the success of the proposed methodology (Figure 3).

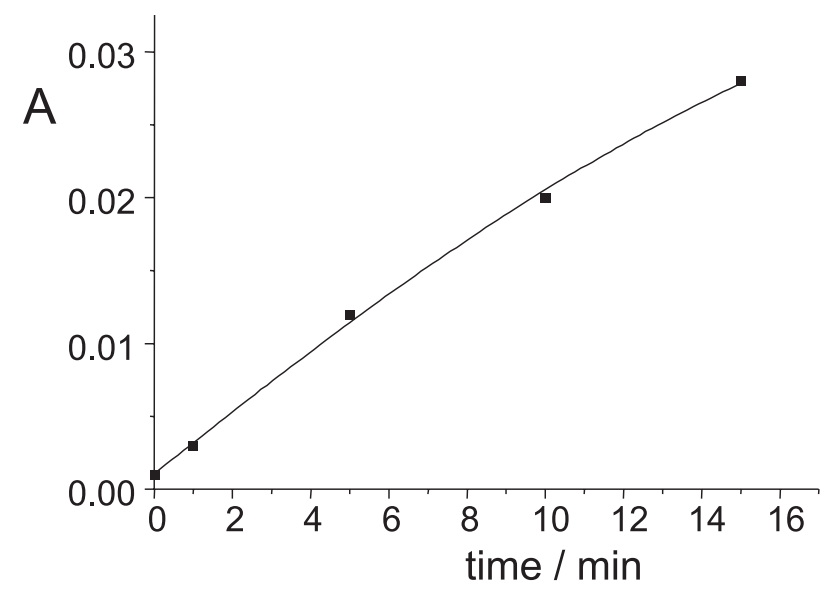

Figure 3. Effect of ultrasonic irradiation time on the oxidation of $10 \mu \mathrm{g}$ of $\mathrm{Cr}(\mathrm{III})$ in $\mathrm{CCl}_{4}$ saturated aqueous solution, monitored by the $\mathrm{Cr}(\mathrm{VI})$-DPC spectrophotometric method. $[\mathrm{Co}(\mathrm{II})]=10 \mu \mathrm{g} \mathrm{mL}^{-1}$.

Validation tests were carried out by adding known quantities of chromium to tap water. More than $95 \%$ of the $\mathrm{Cr}(\mathrm{III})$ added to the sample was oxidized when performing sonication in the presence of $\mathrm{Co}(\mathrm{II})$ and a chlorine radical producing reagent.

\section{Arsine production by hydrogen radical}

In the presence of a hydroxyl scavenger, such as metallic zinc, hydrogen radicals can be produced during water sonolysis. This species can be used for hydrogenation of organic compounds, for hydride generation and to reduce other chemical species. The hydride generation technique has been employed for the determination of several elements, such as $\mathrm{As}, \mathrm{Se}, \mathrm{Sb}, \mathrm{Ge}$, $\mathrm{Pb}$ and $\mathrm{Sn}$, in different matrixes. Arsine has been generated after hydrogen radical production from $\mathrm{NaBH}_{4}$ or by the reaction between metallic zinc and a mineral acid, e.g. $\mathrm{HCl}$ or $\mathrm{H}_{2} \mathrm{SO}_{4}$. By irradiating a sample solution in acidic medium (from $1 \times 10^{-4}$ to $1 \times 10^{-1} \mathrm{~mol} \mathrm{~L}^{-1}$ ) in the presence of metallic zinc with ultrasound, arsine was generated by the interaction of $\mathrm{As}(\mathrm{III})$ with the sonochemically produced hydrogen. The conditions were optimized by applying a $2^{3}$ factorial design with a central point. Thus the optimized zinc mass, acid concentration and sonication time were $0.3 \mathrm{~g}, 1 \times 10^{-2} \mathrm{~mol} \mathrm{~L}^{-1}$ and $5 \mathrm{~min}$, respectively.

The suggested mechanism involved in arsine formation is derived from water sonolysis (equation 5), metallic zinc oxidation (equation 6) and hydride generation by the hydrogen radical (equation 7).

$$
\begin{aligned}
& \mathrm{H}_{2} \mathrm{O} \stackrel{M}{\rightarrow} \cdot \mathrm{OH}+\cdot \mathrm{H} \\
& \mathrm{Zn}^{0}+2 \cdot \mathrm{OH} \rightarrow \mathrm{Zn}(\mathrm{OH})_{2}+2 \cdot \mathrm{H} \\
& \mathrm{As}^{3+}+3 \cdot \mathrm{H} \rightarrow \mathrm{AsH}_{3}
\end{aligned}
$$

Experimental evidence indicates that arsine generation with metallic zinc assisted by ultrasonic irradiation also occurs in neutral medium. However, the arsine production rate was lower than that observed in acidic medium and the precision of the procedure was also affected, due to the interaction of $\mathrm{As}(\mathrm{III})$ with $\mathrm{Zn}(\mathrm{OH})_{2}$ produced in a neutral medium.

In acidic medium the arsine generation assisted by ultrasonic irradiation was linear $(r=0.9997)$ and the absorbance variation of Ag-DDTC-As complex with As was $\mathrm{A}=1.192 \mathrm{Q}_{\mathrm{As}(\mu \mathrm{g})}-0.016$, from 0.05 to $0.5 \mu \mathrm{g}$ of As. The detection limit $(3 \sigma)$, expressed in As concentration, was $2.3 \mu \mathrm{g} \mathrm{L}^{-1}$. The precision of this arsine generation procedure was evaluated with a $0.1 \mu \mathrm{g}$ As standard solution and showed good precision $(3.5 \%, \mathrm{~N}=10)$.

A recuperation test was performed in urine samples by adding $0.1 \mu \mathrm{g}$ of As(III) to each solution before acidic treatment. The arsenic concentration of the solutions with and without the As spike addition was also determined by atomic absorption spectrometry. The data of recovery test are presented in Table 1.

Table 1. Recovery test of $0.1 \mu \mathrm{g}$ of As from three urine samples by employing ultrasonic assisted production of arsine $(\mathrm{N}=5)$.

\begin{tabular}{ccc}
\hline Sample & $\begin{array}{c}\text { Mass of As Recovery } \\
(\mu \mathrm{g})\end{array}$ & $\begin{array}{c}\text { Recovery } \\
(\%)\end{array}$ \\
\hline A & $0.10 \pm 0.01$ & $99 \pm 2$ \\
B & $0.097 \pm 0.005$ & $97 \pm 4$ \\
C & $0.094 \pm 0.006$ & $94 \pm 2$ \\
\hline
\end{tabular}

\section{Conclusions}

The generation of reagents by ultrasonic irradiation of aqueous solutions of different species is worthwhile due to cost, simplicity, and operational time. From this point of view, one drop of $\mathrm{CCl}_{4}$ is enough to prepare $1 \mathrm{~L}$ of $\mathrm{CCl}_{4}$ saturated aqueous solution, which is able to quantitatively oxidize $\mathrm{Cr}(\mathrm{III}), \mathrm{Mn}$ (II), $\mathrm{Fe}$ (II) and $\mathrm{Co}(\mathrm{II})$ during sonication. In addition to this, the waste from an analytical procedure containing chloromethane species can be used to generate volatile species, which can be separated by the pervaporation technique, since the chemicals produced 
with this process could be at an adequate purity level to be used in sample preparation steps.

The scavenger hydroxyl radical, produced during water sonication, is an important tool in order to generate the reducing environment required for several procedures, such as reduction of $\mathrm{Cr}(\mathrm{VI})$ to $\mathrm{Cr}(\mathrm{III})$ in waste water treatment, and was successfully used for hydride formation.

\section{References}

1. Mason, T. J.; Lorimer, J. P.; Sonochemistry: Theory, Applications and Uses of Ultrasound in Chemistry, Ellis Horwood: Chichester, UK, 1988.

2. Suslick, K.S.; Science 1990, 247, 1439.

3. Hua, I.; Hoffmann, M. R.; Environ. Sci. Technol. 1997, 31, 2237.

4. Wakeford, C. A.; Blackburn, R.; Lickiss, P. D.; Ultrasonics Sonochem. 1999, 6, 141.

5. Sousa, C. S.; Korn, M.; Anal. Chim. Acta 2001, 444, 309.
6. Akcay, M.; Elik, A.; Savasci, S.; Analyst 1989, 114, 1079.

7. El Azouzi, H.; Cervera, M.L.; de la Guardia, M.; J. Anal. Atom. Spectrom. 1998, 13, 533.

8. Nascentes, C. C.; Korn, M.; Arruda, M.A.Z.; Microchem. J. 2001, 69, 37.

9. Suslick, K. S.; Hammerton, D. A.; Cline Jr., R. E.; J. Am. Chem. Soc., 1986, 108, 5641.

10. Borges, S. S.; Korn, M.; Quim. Nova 2002, 25, 558.

11. Borges, S. S.; Andrade, M. V. A. S.; Korn, M.; Abstracts of $11^{\circ}$ Encontro Nacional de Química Analítica, Campinas, Brazil, 2001.

12. Korn, M.; Primo, P. M.; Sousa, C. S.; Microchem. J. 2002, 73, 273.

13. Nascentes, C. C.; Korn, M.; Sousa, C. S.; Arruda, M. A. Z.; J. Braz. Chem. Soc. 2001, 12, 57.

Received: October 19, 2002 Published on the web: April 14, 2003 